\title{
THE IMPACT OF STRATEGIC LANGUAGE ON EMPLOYEE AMBIDEXTERITY
}

\author{
Cau Ngoc Nguyen \\ Lecturer, School of Business \& Management, RMIT University Vietnam, \\ Ho Chi Minh City, Vietnam \\ Albi Alikaj and Wei Ning \\ Assistant Professor, School of Business \& Industry, Jacksonville State University, \\ Jacksonville, Alabama, USA \\ Quoc Nam Tran \\ Lecturer, Faculty of Economics \& Business, Hoa Sen University, \\ Ho Chi Minh City, Vietnam
}

\begin{abstract}
The purpose of this paper is to explore the impact that the leader's spoken communication has on employee ambidexterity. Specifically, the study draws from the strategic leadership perspective and motivating language theory literature to posit that the leader's use of motivating language can foster employee exploitative and explorative behaviors. This paper also investigates how these behaviors can be beneficial to the firm by investigating its impact on employee absenteeism and turnover intention. Design/Methodology: This study is based on a cross-sectional survey of 206 Vietnamese employees. After several stringent tests for reliability, validity, multicollinearity, model fit, and model quality, the data is analyzed with a partial least squares structural equation model. The findings indicate that leaders can strategically use verbal communication to encourage the employees' individual ambidexterity. Further analyses show that employee ambidexterity generally has a favorable impact on work-related outcomes by decreasing absenteeism and turnover intention. This study suggests that employee ambidexterity can be stimulated with verbal communication that gives clear directions, gives a higher meaning to the employee's work, and shows genuine care for the employee as an individual. As a practical implication, this may highlight the need for firms to implement training programs for managers to effectively communicate with their employees
\end{abstract}

Key words: Ambidexterity, Motivating Language, strategic leadership 
Cite this Article: Cau Ngoc Nguyen, Albi Alikaj,Wei Ning and Quoc Nam Tran, The Impact of Strategic Language on Employee Ambidexterity, International Journal of Management, 11(12), 2020,pp. 1480-1495.

http://iaeme.com/Home/issue/IJM?Volume=11\&Issue $=12$

\section{INTRODUCTION}

The past four decades has witnessed a proliferation of interest in theory and research on organizational ambidexterity. Organizational ambidexterity refers to the ability to explore new opportunities while exploiting existing competencies (Cao et al., 2009; Tushman and O'Reilly, 1996). Ambidexterity exists for all levels of an organization, ranging from the organizational level down to the individual employee (Kauppila and Tempelaar, 2016; Raisch et al., 2009). At the individual level, ambidexterity refers to the extent to which an individual pursues exploitative and explorative behaviors in the workplace (Bledow et al., 2009; Kauppila and Tempelaar, 2016; Mom et al., 2009). Individual ambidexterity (IA) is not only a possible level at which firms can reconcile exploitation and exploration, but it is also a level that is crucial for gaining synergies between exploitation and exploration at the organizational level (Kauppila and Tempelaar, 2016). According to Kauppila and Tempelaar (2016), for ambidexterity to be present at any level of the firm, it "requires the agency and discretion of ambidextrous individuals - be they all employees or a small group of managers- to allocate resources and manage the cross-fertilization between explorative and exploitative activities" (Kauppila and Tempelaar, 2016, p. 1020).

The significance of IA has also been discussed beyond the ambidexterity literature (Kauppila and Tempelaar, 2016). The literature on work design and motivation have documented that present job roles require employees to engage in increasingly diverse tasks (Griffin et al., 2007) and take initiative in developing and pursuing their job goals (Frese and Fay, 2001). These scholars argue for work roles involving characteristics of ambidexterity to increase interest and motivation for employees (Adler et al., 1999). As Parker (2014) posits, ambidexterity can be a form of job enrichment for individuals in mundane positions because the combination of tasks involving exploitation and exploration brings more value to the work. Similarly, Birkinshaw and Gupta (2013) argued that even in the most ordinary job position, employees face some version of the ambidexterity dilemma, such as the amount of time one should spend exploiting existing skills for the firm's benefit versus the amount of time one should spend trying to develop a new skill and/or help the firm in innovative ways. Furthermore, Miron-Spektor and associates (2011) found that workers who integrated exploitation and exploration were more creative than those that only explore because the combination of the conflicting demands prevented workers from relying on conventional thinking.

Despite these claims, ambidexterity research at the individual level remains scarce. Case in point, a recent meta-analysis by Junni and associates (2013) found only about 4\% of all empirical research on ambidexterity was analyzed at this level. Most studies on ambidexterity have taken a macro-level perspective, thus providing the literature with in-depth knowledge of the antecedents and outcomes of ambidexterity at the organizational level (Keller and Weibler, 2015; Raisch and Birkinshaw, 2008). However, this increased emphasis on the macro-level has left the ambidexterity literature with a limited conceptual and empirically validated understanding about ambidexterity at the individual level (Mom et al., 2009; Raisch and Birkinshaw, 2008), resulting in the explicit need for a more focused analysis of IA (Caniëls et al., 2017; Junni et al., 2013; Prieto and Pilar Pérez Santana, 2012).

To answer these calls, we adopted the strategic leadership perspective, which suggests that certain leader behaviors can influence employees to adapt organizational values (Bass, 1985), which may foster employee ambidexterity. Among the vast literature on leadership strategies, 
we focus on the leader's use of motivating language (Mayfield and Mayfield, 2002; Sullivan, 1988) as one strategy to enhance employees' individual ambidexterity because of its noted impact in changing employees' psychological states (Mayfield and Mayfield, 2018). In this investigation, we examined how the leader's use of motivating language can encourage employees to engage in more explorative and exploitative behaviors and how those behaviors can impact employee success. Therefore, the purpose of this study is two-fold. First, we add evidence to the ambidexterity literature by empirically analyzing how the leader can implement effective motivating language use as a strategy to enhance employee ambidexterity behaviors. Second, we examine how employee ambidexterity can improve two key work attitudes: absenteeism and turnover intention.

\section{LITERATURE REVIEW AND HYPOTHESIS DEVELOPMENT}

\subsection{Individual Ambidexterity}

The extant literature conceptualized (Bledow et al., 2009; Mom et al., 2009) individual ambidexterity as a multidimensional construct that captures the degree to which an employee pursues explorative or exploitative behaviors (Mom et al., 2009). Exploitative behaviors require some degree of refinement or improvement to a skill or knowledge in order to complete a task, whereas exploration involves gaining a new skill or knowledge to find alternative or new ways to complete a task. Given that IA is composed of distinct dimensions of exploitation and exploration, it can be enhanced through any factors that increase either behaviors, given that it is not at the expense of decreasing one or the other (Mom et al., 2009).

Initially, scholars have suggested that ambidexterity is achieved through structural means (Duncan, 1976; Tushman and O'Reilly, 1996). However, later research proposed that ambidexterity is achieved contextual means (Gibson and Birkinshaw, 2004). From this perspective, the accountability for achieving ambidexterity is shared by each member within the organization. To create a high performing business unit, the top leaders are advised to establish an organizational context that facilitates both alignment and adaptability through appropriate performance management and social support (Gibson and Birkinshaw, 2004). As such, we posit that the literature on motivating language may offer leaders one way to create a contextual environment to foster employee ambidexterity.

\subsection{Motivating Language Theory}

Motivating language theory posits that leaders can influence employee psychological states with strategic use of language (Sullivan, 1988). According to motivating language theory, motivating language (ML) encompasses three types of spoken communication: directiongiving, meaning-making, and empathetic language. Direction-giving language explicates one's objectives, such as the expectations for the time, efficiency, and method for the job, as well as the incentives associated with achieving the goals. Additionally, the direction-giving language includes input from the task. If job feedback is given constructively, it has the potential to improve the learning, self-efficacy, and efficiency of the employee (Mayfield and Mayfield, 2018).

The second type is meaning-making language, which aligns the personal goals of an employee with a higher purpose. This mode of speech imparts to the employee the distinct appreciation of his / her skillsets and helps guide the talents of that individual towards organizational contribution. Lastly, empathetic language conveys encouragement and concern to an employee to express genuine care for the well-being of an employee outside of the workplace (Mayfield and Mayfield, 2018). Through meaning-making language, the leader can bond with the employee on an emotional level. 
Motivating language theory relies on four basic assumptions. First, the leader has to align their words with their actions. The reputation of the leader comes from the actions which represent the messages they have spoken (Mayfield and Mayfield, 2018). The second assumption is that motivating language reflects most leader-to-employee work-related communication. This is consistent with Sullivan's conception of linguistics theory and its boundaries (Sullivan, 1988). Third, the employee must accurately understand the message conveyed by the leader. Even though motivating language is specifically defined as the leader's spoken language, employees must understand the meaning of it. Lastly, all three dimensions of motivating language must be strategically coordinated to achieve the best results (Mayfield and Mayfield, 2018).

\subsection{Motivating Language and Individual Ambidexterity}

Motivation has been identified in various studies as being a key psychological determinant of worker behavior (Caniëls et al., 2017; Ryan and Deci, 2000; Tremblay et al., 2009). Equally important, strategic communication can be influential in driving employee motivation and performance (Mayfield and Mayfield, 2018; Sullivan, 1988). Motivating language theory provides insights into how a leader's conscious application of speech can influence employee behavior (e.g., Mayfield and Mayfield, 2004). Thus, this paper draws from motivating language theory to propose that a leader's use of motivating language and its three dimensions of speech can foster employees' individual ambidexterity is several ways.

First, the manager's use of direction-giving language can help develop individual exploitative behaviors. Direction-giving language promotes routine tasks by articulating how to effectively and efficiently do things the right way and bringing informational transparency to the work (Mayfield and Mayfield, 2018). When managers use direction-giving language, they can reduce role ambiguity, clarify expectations and contingencies, and explain the procedures that can be taken to accomplish the task. With such clear information, the employee can focus his or her existing knowledge to perform the work. Direction-giving language also includes coaching and constructive task feedback which can promote learning and knowledge refinement (Mayfield and Mayfield, 2018). With the use of direction-giving language, managers can give negative feedback in constructive ways to target specific behaviors and offer attainable steps for improvements (Robbins and Hunsaker, 2012). Competent managerial use of ML can expedite constructive feedback to their employees and focus on relaying information about the available resources that the firm offers, such as mentors or training, for the employee to hone their existing knowledge for better job performance in the future (Mayfield and Mayfield, 2018).

Second, MLT suggests that empathetic language can encourage employees to take risks which can promote explorative behaviors. With effective use of empathetic language, the manager can send messages of civility, empathy, and compassion for any work scenarios (Mayfield and Mayfield, 2018). These messages can show the employee that they are supported in both positive and negative work situations. In positive situations, such as when an individual successfully overcomes a difficult challenge, managers can provide accolades. For negative scenarios, such as setbacks in projects or tasks, managerial use of ML can provide reassurance and support. These perceptions of such support can build trust between the employees and the managers, which can foster risk-taking and experimentation (Neves and Eisenberger, 2014).

Third, meaning-making language encourages employees to develop unique skills and approaches to problem-solving (Mayfield and Mayfield, 2018), which can foster their explorative behaviors. Meaning-making language is a tool that aligns the employee's personal goals with organizational goals. Mean-making language spurs 'garden variety creativity', or new and innovative ways to perform often routine jobs (Mayfield and Mayfield, 2018). 
Managers utilizing meaning-making language can visibly credit their employee for specific creative initiatives that contributes to advancing organizational goals (Mayfield and Mayfield, 2018). Previous studies have supported these assertions, consistently linking ML to higher innovation and creativity performance (Mayfield and Mayfield, 2004, 2017; Wang et al., 2009). Mayfield and Mayfield (2004), for instance, found that, for every 10\% increase in ML use, there is a $2.7 \%$ increase in employee innovation. When employees are more creative and innovative, they are more likely to think 'outside of the box' to experiment and find unconventional means to carry out their tasks or find alternative solutions to solve problems (Good and Michel, 2013; Kauppila and Tempelaar, 2016; Keller and Weibler, 2015; Mom et al., 2007). ML can be a useful strategy that leaders can utilize to motivate and cultivate their employees' behaviors. With the proper use of direction-giving language, empathetic language, and meaning-making language, the manager can foster their employees' ambidexterity in the workplace.

Accordingly, the following hypothesis is made:

Hypothesis 1: There is a significant and positive relationship between the manager's use of motivating language and the employees' individual ambidexterity.

\subsection{Individual Ambidexterity and Absenteeism}

There have been several, but similar, definitions of absenteeism provided by the literature. For example, Rogers and Herting (1993) defined absenteeism as a choice made by an individual to be absent from work due to reasons other than illness. Likewise, Martocchio and Jimeno (2003) stated that absenteeism is simply "constitutes a single day of missed work" (p. 230). The general agreement in the literature of the definition of absenteeism seems to be that of Harrison and Price (2003) (Gosselin et al., 2013). Harrison and Price (2003) posit that absenteeism occurs when there is "a lack of physical presence at a behavior setting when and where one is expected to be" (Harrison \& Price, 2003, p. 204). This research adopts the definition of Rogers and Herting (1993) to define absenteeism as the employee's attitude toward missing work for reasons other than illness.

In this study, we posit that an employee with higher levels of IA is less likely to exhibit absent behaviors. Ambidexterity requires the individual to alternate and/or combine exploitative and explorative behaviors (Mom et al., 2015). This diversity in work tasks can lead to higher job enrichment (Griffin et al., 2007). With higher levels of job enrichment, even the most mundane job tasks can carry more meaning and be more interesting (Parker, 2014) which can lead to lower employee absenteeism.

Hypothesis 2: There is a significant and negative relationship between the employees' individual ambidexterity and absenteeism.

\subsection{Individual Ambidexterity and Turnover Intention}

We argue that an individual's ambidexterity can reduce the likelihood of his/her turnover intention for two main reasons. The first reason is that a more ambidextrous individual is typically more flexible (Good and Michel, 2013). The higher level of flexibility means that the employee can adjust to the rapid changes in the workplace (Feldman and Pentland, 2003). When a significant change occurs in the organization, the ambidextrous individual is more likely to find a way to adjust instead of giving up and wanting to leave the organization. In addition, an employee with higher IA tends to feel that they have higher job autonomy (Jasmand et al., 2012; Rogan and Mors, 2014; Sok and O'Cass, 2015). With higher perceptions of job autonomy, the employee feels more in control and freedom in his/her work leading to higher commitment and lower turnover intentions (Dysvik and Kuvass, 2013). 
Hypothesis 3: There is a significant and negative relationship between the employees' individual ambidexterity and turnover intention.

Figure 1 presents the conceptual model with the hypothesized relationships between the variables.

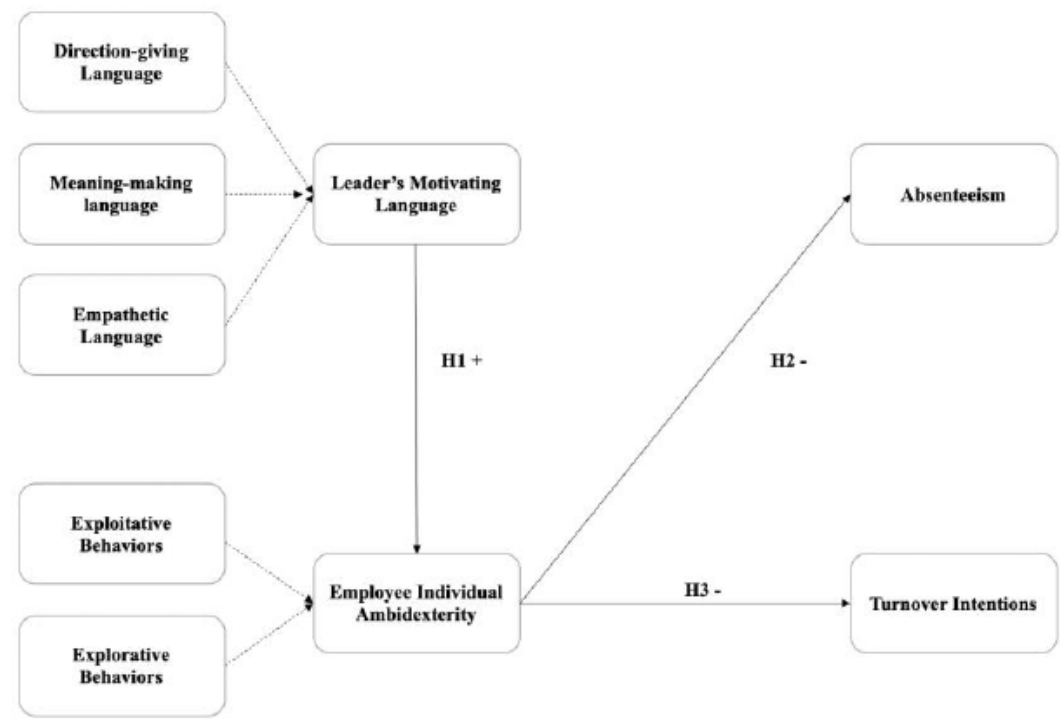

Figure 1 Conceptual Model

Source: - Data Analysis

\section{DATA COLLECTION}

The participants for this research were drawn from Amazon's Mechanical Turk which is a website that provides a mechanism for posting job assignments. Individuals around the world can complete job assignments for the stated compensation. This potential pool of respondents is a useful method for recruiting subjects for psychological experiments or surveys (Nguyen et al., 2015). Huff and Tingley (2014) investigated the Mechanical Turk employee respondents pool and determined these respondents' characteristics were consistent with the work characteristics of the general working population. Also, several researchers (e.g., Buhrmester et al., 2011) have verified that the Mechanical Turk responses are generalizable to the population. Furthermore, Peer and colleagues (2014) found the Mechanical Turk website's incentives provided respondents with strong motivation to conscientiously and accurately answer survey items for research.

Respondents were recruited by posting a solicitation for Vietnamese workers. Respondents were provided a monetary incentive of US $\$ 0.50$ for survey completion about their workplace environment. Overall, 206 employees completed the survey, all of which were from various industries. By drawing data from varying industries, we sought to improve the external validity of our research. Most of the participants were male (62\%). The employees' average age was 34.4 , with average job tenure of 4.8 years. The majority of respondents held at least a bachelor's degree $(58 \%)$.

\section{MEASURES}

\subsection{Individual Ambidexterity}

This study adopts the scales that Mom and colleagues (2009) developed to measure individual exploitation and exploration behaviors. A total of 14 items (seven each) was used to ascertain the extent to which an individual engaged in work-related activities that are characterized as 
exploitative or explorative (e.g., Kauppila and Tempelaar, 2016; Li et al., 2015; Mom et al., 2009; Torres et al., 2015). A seven-point Likert scale ranging from $1=$ to a very small extent, $2=$ to a small extent, $3=$ to a slightly below average extent, $4=$ to an average extent, $5=$ to a slightly above average extent, $6=$ to a large extent, to $7=$ to a very large extent was used for the individual ambidexterity indicator scale. A sample of exploitative behaviors includes "Activities which you carry out as if it were routine", "Activities of which it is clear to you how to conduct them", and "Activities primarily focused on achieving short-term goals". Some of the statements used to measure explorative behaviors include "Searching for new possibilities with respect to my work", "Evaluating diverse options with respect to my work", and "Activities requiring you to learn new skills or knowledge". Individual ambidexterity was operationalized as a second-order latent variable comprising of exploitative and explorative behaviors (Kauppila and Tempelaar, 2016; Li et al., 2015; Mom et al., 2009; Torres et al., 2015).

\subsection{Motivating Language}

To capture the leader's motivating language use, this study adopted Mayfield and colleagues' (1995) motivating language scale. The scale is comprised of subscales that include how often the employees' leader uses direction-giving language, meaning-making language, and empathetic language. The indicators were measured on a five-point Likert scale, ranging from $1=$ very seldom to $5=$ always.

Worker attitudes: The scales for absenteeism and turnover intention were both measured on a five-point Likert scale, ranging from $1=$ strongly disagree to $5=$ strongly agree. Turnover intention is measured with a five-item scale developed by Bozeman and Perrewe (2001). Absenteeism is measured using a ten-item scale attitude toward absenteeism scale (Mayfield and Mayfield, 2009).

Control Variables: This study controlled for employee age because several scholars have found that age is negatively related to ambidexterity (Kauppila and Tempelaar, 2010; 2016; Mom et al., 2009). This paper also included control variables for tenure (years) with the firm and years under the same manager because the experience may influence ambidexterity as increased levels of experience are associated with the employee's increased ability to interpret and deal with more ambiguous cues (Mom et al., 2009). Also, because performing the same job for an extended time may be associated with lower levels of creativity (March, 1991), this study controlled for position tenure in years. Several researchers have also shown that increasing levels of education can positively impact an individual's cognitive ability to process information and learning which can relate to his or her ambidexterity (Kauppila and Tempelaar, 2016; T. Keller and Weibler, 2015; Mom et al., 2007). Thus, education effects were controlled using a five-point measure (high school, associate's degree, bachelor's degree, master's degree, and doctorate's). Furthermore, workers who are higher in the firm's hierarchy may experience greater pressure and higher autonomy to exhibit ambidexterity (Mom et al., 2009), which is why a measure of hierarchical level (associate/worker, team supervisor, middle manager, top management) was also included.

\section{METHODOLOGY}

\subsection{Statistical Technique}

This study uses partial least squares structural equation modeling (PLS-SEM). PLS-SEM is used for the investigation for several reasons. First, this technique allows for the simultaneous estimation of two or more relationships among variables (Shook et al., 2004). Second, this method allows for the estimation of latent variables. Third, this type of analysis generally produces more valid estimations because it controls for measurement error (Dion, 2008). Lastly, 
the relatively small sample sizes and a large number of items produced an unfavorable item-tocases ratio. Therefore, we rely on PLS-SEM due to its relaxed requirements on sample and data distribution (Kock, 2017).

To analyze the data, this study used WarpPLS 6.0 (Kock, 2017). This statistical program is specifically dedicated to PLS-SEM. Previous studies have shown that this program is capable of analyzing a variety of PLS models and producing reliable results (Kock, 2013; Kock and Syn, 2016). Table 1 shows the means, standard deviations, and correlations among the variables for the sample.

Table 1 Descriptive Statistics

\begin{tabular}{lrlllllllllll}
\hline & Mean & SD & 1 & $\mathbf{2}$ & $\mathbf{3}$ & $\mathbf{4}$ & $\mathbf{5}$ & $\mathbf{6}$ & $\mathbf{7}$ & $\mathbf{8}$ & $\mathbf{9}$ & 10 \\
\hline 1. Mot. language & 3.09 & 1.16 & $(0.91)$ & & & & & & & & \\
2. Ambidexterity & 4.45 & 1.54 & $0.35^{* *}$ & $(0.85)$ & & & & & & & \\
3. Absenteeism & 3.78 & 1.40 & $-0.10^{*}$ & $-0.28^{* *}$ & $(0.86)$ & & & & & & & \\
4. T0 intention & 3.13 & 1.23 & $-0.22^{*}$ & $-0.04^{*}$ & $0.09^{*}$ & $(0.88)$ & & & & & & \\
5. Age & 34.39 & 10.88 & $-0.16^{*}$ & -0.03 & -0.05 & -0.08 & & & & & & \\
6. Education & 2.75 & 1.01 & 0.13 & 0.06 & $0.21^{*}$ & 0.12 & 0.08 & & & & & \\
7. Job level & 1.98 & 0.97 & 0.11 & -0.05 & $0.28^{* *}$ & -0.03 & 0.13 & 0.26 & & & & \\
8. Job tenure & 4.84 & 5.01 & -0.06 & -0.02 & -0.06 & $-0.16^{*}$ & $0.58^{* *}$ & $0.11^{* *}$ & 0.09 & & & \\
9. Firm tenure & 5.84 & 6.30 & -0.08 & -0.02 & -0.02 & $-0.17 *$ & $0.61^{* *}$ & 0.08 & 0.19 & $0.69^{* *}$ & & \\
10. Same boss & 4.07 & 4.70 & 0.01 & 0.00 & 0.07 & -0.13 & $0.45^{* *}$ & 0.09 & $0.21^{*}$ & $0.67^{* *}$ & $0.62^{* *}$ & \\
11. Firm size & 1.99 & 0.70 & -0.06 & 0.02 & 0.07 & -0.01 & 0.02 & 0.02 & -0.08 & 0.00 & 0.08 & -0.08 \\
VIF & & & 1.59 & 1.70 & 1.56 & 1.93 & & & & & & \\
\hline
\end{tabular}

Notes: $\mathrm{SD}$ = standard deviation; Mot. language = motivating language; Ambidexterity= employee individual ambidexterity; T0 intention= employee turnover intention; Same boss = employee tenure under the same leader; VIF = Variance Inflation Factor, ${ }^{*} \mathrm{p}<$ $.05,{ }^{* *} \mathrm{p}<.01$. Composite reliability values in the diagonal.

Source: Data Analysis

\subsection{Validity and Reliability Tests}

Validity, reliability, and multicollinearity tests were conducted to determine the strengths of the variables. First, confirmatory factor analysis was used to establish whether the latent variables passed acceptable measures for convergent and discriminant validity. The loading of all indicators should be at least 0.50 on their hypothesized component as well as show significance at the $\mathrm{r}<.05$ level (Fornell and Larcker, 1981). Three indicators of absenteeism did not load properly $(>0.50)$ in the sample; therefore, they were removed. The loadings for the items used in this study are shown in Table 2. All of the standardized factor loadings included in this investigation were significant at the $r<.001$ level. This indicates that the instrument has acceptable convergent validity (Hair et al., 2010). 
Table 2 Latent Variables Factor Loadings

\begin{tabular}{|c|c|}
\hline Absenteeism & Results \\
\hline I miss work far more often than my co-workers. & 0.774 \\
\hline I have been reprimanded for the number of my absences. & 0.744 \\
\hline I am often absent from work. & 0.801 \\
\hline I don't care if I have to miss work. & 0.778 \\
\hline Turnover Intention & 0.786 \\
\hline I will probably look for a new job in the near future. & 0.804 \\
\hline At the present time, I am actively searching for another job in a & 0.813 \\
\hline different organization. & 0.777 \\
\hline It is unlikely that I will actively look for a different organization to & \\
\hline work for in the next year. & 0.921 \\
\hline Motivating language & 0.804 \\
\hline Direction-giving language & 0.898 \\
\hline Meaning-making language & 0.862 \\
\hline Empathetic language & 0.862 \\
\hline Individual Ambidexterity & \\
\hline Exploitation & \\
\hline Exploration & \\
\hline
\end{tabular}

Notes: Motivating language and individual ambidexterity are second-order reflective variables. The loadings for the first-level latent variables are shown here. All loadings are significant at the $\rho<.001$ level

\section{Source: - Data Analysis}

A test for discriminant validity was conducted by comparing the inter-construct correlations with the square roots of their respected average variances extracted (AVEs) (Bollen, 1989; Chin, Marcolin, and Newsted, 2003; Fornell and Larcker, 1981). The data showed that the square roots of AVEs for each latent variable are greater compared to any correlation relating to another latent variable. This suggests that each of the latent variables used in the study has satisfactory discriminant validity.

Reliability and collinearity tests were also conducted for the sample. Measurement model reliability was assessed using composite reliability (CR). CR considers the indicators' different loadings. To display acceptable reliability, a latent variable's CR should be 0.70 or higher (Hair et al., 2010; Nunnally and Bernstein, 1994). All values for CR for the three samples pass these thresholds.

Full collinearity variance inflation factors (VIFs) are calculated based on a full collinearity test (Kock and Lynn, 2012), which "enables the identification of not only vertical but also lateral collinearity and allows for a test of collinearity involving all latent variables in a model" (Kock, 2017, p. 78). Full Collinearity VIFs can also be used to effectively

check for common method bias (Kock and Lynn, 2012). Full collinearity VIFS of 3.3 or lower 
indicate no multicollinearity in the model and no existence of common method bias (Kock and Lynn, 2012). There were no latent variables that exceeded this threshold. This suggests that there is no existence of multicollinearity or common method bias (Kock, 2017). CR and VIF values for the independent and dependent variables are also shown in Table 1. In summary, the measurement models pass several stringent tests of validity, reliability, collinearity, and common method bias. This indicates that the results of the SEM can be trusted and are free from data measurement problems (Kline, 2015; Schumacker and Lomax, 2004).

\subsection{Model Fit and Model Quality}

Table 3 presents the indices used to determine the model fit and model quality. To assess the model fit, the average path coefficient (APC), average R-squared (ARS), and average inflation factor were calculated. The literature recommends that the values for both the APC and ARS be significant at least at the $\rho<.05$ level, while the AVIF should be lower than 5 (Hair, et al., 2010; Kline, 2005; Kock, 2017). The results of these tests $(\mathrm{APC}=0.27$; ARS $=0.36$; and AVIF $=1.37)$ indicate that the data is a good fit for the proposed model.

Table 3 Model Fit and Model Quality Indices

\begin{tabular}{|c|c|c|c|c|c|}
\hline \multicolumn{3}{|c|}{ Model Fit Indices } & \multicolumn{3}{c|}{ Model Quality Indices } \\
\hline APC & ARS & AVIF & SPR & RSCR & NLBCDR \\
\hline $0.27^{* *}$ & $0.36^{* *}$ & 1.37 & 0.88 & 0.99 & 0.79 \\
\hline
\end{tabular}

Notes: $* \mathrm{p}<.05, * * \mathrm{p}<.01$

Source: - Data Analysis

Several model quality indices, as presented in Table 3, were provided by WarpPLS 6.0 to assess the quality of the models. Sympson's paradox ratio (SPR) is "a measure of the extent to which the model is free from Simpson's paradox instances" (Kock, 2017, p. 64). Simpson's paradox indicates a possible causality problem, suggesting that a hypothesized path is either implausible or reversed. The ideal coefficient for SPR is 1 , meaning that there are no instances of Simpson's paradox in the model; "acceptable values of SPR are equal to or greater than 0.7 , meaning that at least 70 percent of the paths in a model is free from Simpson's paradox (Kock, 2017 , p. 64). The coefficient for the model is 0.88 . This suggests that the paths in the model are $88 \%$ free from Simpson's paradox. In addition, the R-squared contribution ratio (RSCR) is "a measure of the extent to which a model is free from negative R-squared contributions" (Kock, 2017, p. 64), which also occurs with Simpson's paradox. This index is similar to SPR, with the key difference that it is calculated based on actual values of $r$-squared contributions, not on the number of paths where these contributions have specific signs. Ideally, RSCR should be 1, but acceptable values of RSCR are equal to or greater than 0.9. This means that "the sum of positive R-squared contributions in the model makes up at least 90 percent of the total sum of the absolute R-squared contributions in the model" (Kock, 2017, p. 64). The index calculated shows that the model has an acceptable RSCR (0.99). Furthermore, WarpPLS 6.0 also provided a calculation for nonlinear bivariate causality direction ratio (NLBCDR). This index is "a measure of the extent to which bivariate nonlinear coefficients of association provide support for the hypothesized directions of the causal links in a model" (Kock, 2017, p. 65). Acceptable values of NLBCDR are equal to or greater than 0.7 , "meaning that in at least 70 percent of pathrelated instances in [the] model the support for the reversed hypothesized direction of causality is weak or less" (Kock, 2017, p. 65). "Less" in this context may mean that the support for the reverse hypothesized direction of causality is less than weak, or that the hypothesized direction 
of causality is supported. The values of NLBCDR for the model $(0.79)$ is an acceptable value. In summary, the model quality indices- SPR, RSCR, and NLBCDR, indicate that the model is well specified and free from Simpson's paradox.

\subsection{Hypotheses Testing}

The results of the hypotheses tests are presented in Figure 2 and Table 4. Hypothesis 1 stated that the leader's use of motivating language can significantly and positively influence the employees' IA behaviors. The results show support for Hypothesis 1 as the path coefficient is positive and significant at the $1 \%$ level $(\beta=0.46)$. The analysis reveals that the leader's motivating language use in our model explains $24 \%$ of the variance in IA behaviors for these employees.

Hypothesis 2 argued that the employee's IA behaviors have a significant and negative association with his/her absenteeism. The path coefficient is negative $\left(\beta=-0.20, \mathrm{R}^{2}=0.24\right)$ and significant at the $5 \%$ level. Thus, Hypothesis 2 is supported. Hypothesis 3 stated that there is a significant and negative relationship between employees' IA behaviors and turnover intention. This hypothesis is also supported as the results show a negative coefficient $\left(\beta=-0.15, R^{2}=\right.$ 0.36 ), significant at the $5 \%$ level.

Also shown in Table 4 are the effect sizes for each of the relationships. These effect sizes, calculated in WarpPLS, are similar to Cohen's (1988) $f$-squared coefficients. They are calculated using a different procedure, but they have a similar interpretation (Kock, 2017). The effect sizes indicated by path coefficients can be interpreted as small, medium, or large. The values that are recommended are 0.02, 0.15, and 0.35, respectively (Cohen, 1988). Any coefficients below 0.02 indicate that the relationship is too weak to be considered relevant (Kock, 2017). The effect sizes indicate that the manager's use of motivating language has a medium effect on employee ambidexterity. Moreover, employee ambidexterity has a small effect on employee absenteeism and turnover intention.

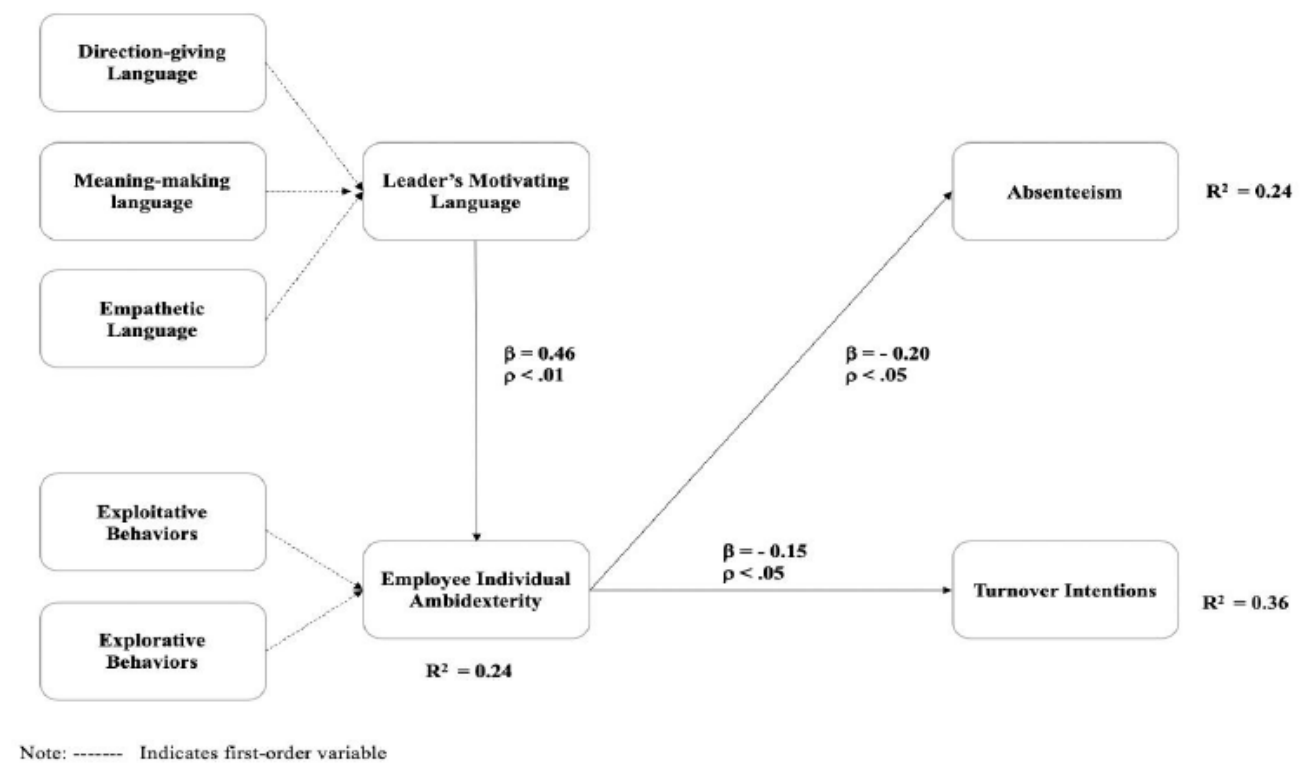

Figure 2 Model Results

Source: - Data Analysis 
Table 4 Path Coefficients and Effect Sizes

\begin{tabular}{|c|c|c|c|}
\hline Path & Coefficient & Effect Size & R2 \\
\hline Mot. language & & & \\
\hline Ambidexterity & $0.46^{* *}$ & 0.22 & 0.24 \\
\hline Ambidexterity & & & \\
\hline Absenteeism & $-0.20^{*}$ & 0.08 & 0.24 \\
\hline TO intention & $-0.15^{*}$ & 0.06 & 0.36 \\
\hline
\end{tabular}

Note: $* \rho<.05, * * \rho<.01$

Source: - Data Analysis

\section{DISCUSSION AND CONCLUSION}

\subsection{Discussion}

Although researchers have long recognized the importance of building employee ambidexterity, research focus has been limited. Drawing from a strategic leadership perspective and motivating language theory, we developed and tested a model to suggest that leaders can use strategic language to foster employee ambidextrous behaviors in the workplace. In addition, we show why firms may want to value such behaviors, as it can have a significant and favorable impact on the employees and their attitudes.

\subsection{Limitations and Directions for Future Research}

Although this study provides some meaningful implications for research and practice, there are several limitations. However, these limitations might prove fruitful for future research. First, there is no temporal separation between the state variables in the model. Although this study presented several calculations for causality in the analyses using experimental indices, incorporating longitudinal data can provide some validation to the causal ordering between the variables. Similarly, future investigations should implement experimental designs to provide additional evidence for the causal relationships in the model.

Second, this investigation relied on employees' self-reports regarding the extent to which they pursued exploitative and explorative behaviors. Although the scales used to assess these behaviors are designed and validated to be self-reported (Kauppila and Tempelaar, 2016; Mom et al., 2009), future research should also investigate whether supervisory or peer assessments of these behaviors yield similar results. Relatedly, we also relied on the employees' perspective of their leader's extent of motivating language use. Future studies should collect and analyze data from the leader's perspective of his/her use of motivating language to examine if the model yields comparable effects.

Third, although the results suggest that there are some differences in the impact of employee IA on work attitudes, we did not test for factors that might cause these differences. Future studies can explore how specific cultural or economic factors may influence employees' IA behaviors and attitudes about their workplace. Fourth, this research captured only the extent to which employees pursued exploitative and explorative behaviors in the workplace. It was unable to determine how these activities intertwine; in other words, whether the individuals engage in these behaviors synchronously or whether they temporally cycled between longer periods of exploitation and exploration (see, Simsek, 2009). Future research should more thoroughly investigate how individuals accommodate and alternate between such behaviors. Fifth, a mixed-methods approach for data collection (i.e. qualitative and quantitative) may offer a richer understanding of the research model. Furthermore, this study investigated 
ambidexterity from the behavioral perspective. It would be interesting to test this model with IA from the cognitive perspective (Good and Michel, 2013; Kauppila and Tempelaar, 2016).

\subsection{Conclusion}

Previous ambidexterity studies have focused on analyzing ambidexterity on a macro level, such as groups and firms (Birkinshaw and Gibson, 2004). In addition, the few studies that have analyzed ambidexterity at the individual level remains fragmented. As such, this paper focuses on all individual-level variables and analyze how IA impact such variables.

Drawing on research on motivating language theory, we hypothesized and found that the leader's use of ML can significantly and positively influence employees' ambidextrous behaviors. We also demonstrated that these behaviors can lead to several favorable employee outcomes including, reducing absenteeism and turnover intention.

\section{ACKNOWLEDGEMENT}

The Study was supported by the Youth Incubator for Science and Technology Program, managed by Youth Development Science and Technology Center - Ho Chi Minh Communist Youth Union and Department of Science and Technology of Ho Chi Minh City, the contract No. 35/2019/HD-kHCN-VU.

\section{REFERENCES}

[1] Adler, P. S., Goldoftas, B., Levine, D. I. (1999). Flexibility versus efficiency? A case study of model changeovers in the Toyota production system, Organization Science, 10(1), 43-68.

[2] Bass, B. M. (1990). From transactional to transformational leadership: Learning to share the vision, Organizational Dynamics, 18(3), 19-32.

[3] Birkinshaw, J. and Gibson, C. (2004). Review building ambidexterity into an organization, MIT Sloan Management Review, 45(4), 47-55.

[4] Birkinshaw, J. and Gupta, K. (2013). Clarifying the distinctive contribution of ambidexterity to the field or organization studies, Academy of Management Perspectives, 27(4), 287-298.

[5] Bledow, R., Frese, M., Anderson, N., Erez, M., and Farr, J. (2009). A dialectic perspective on innovation: Conflicting demands, multiple pathways, and ambidexterity, Industrial and Organizational Psychology, 2(3), 305-337.

[6] Bollen, K. (1989). Structure equations with latent variables, Wiley, New York, NY.

[7] Bozeman, D. P. and Perrewe, P. L. (2001). The effect of item content overlap on Organizational Commitment Questionnaire-turnover cognitions relationships, Journal of Applied Psychology, 86(1), 161-173.

[8] Buhrmester, M., Kwang, T., and Gosling, S. D. (2011). Amazon's mechanical turk: A new source of inexpensive, yet high-quality, data? Perspective on Psychological Science, 6(1), 3-5.

[9] Caniëls, M., Neghina, C., and Schaetsaert, N. (2017). Ambidexterity of employees: The role of empowerment and knowledge sharing, Journal of Knowledge Management, 21(5), 1098-1119.

[10] Cao, Q., Gedajlovic, E., and Zhang, H. (2009). Unpacking organizational ambidexterity: Dimensions, contingencies, and synergistic effects, Organization Science, 20(4), 781-796.

[11] Cohen, J. (1988). Statistical power analysis for the behavioral sciences, Lawrence Erlbaum, Hillsdale, NJ.

[12] Dion, P. A. (2008). Interpreting structural equation modeling results: a reply to Martin and Cullen, Journal of Business Ethics, 83(3), 365-368.

[13] Duncan, R. (1976). The ambidextrous organization: Designing dual structures for innovation in R. H. Killman, L. R. Pondy, and D. Sleven (Eds.), The Management of Organization, NorthHolland, New York, NY, 167-188. 
[14] Dysvik, A. and Kuvass, B. (2013). Perceived job autonomy and turnover intention: The moderating role of perceived supervisor support, European Journal of Work and Organizational Psychology, 22(5), 563-573.

[15] Feldman, M. S. and Pentland, B. T. (2003). Reconceptualizing organizational routines as a source of flexibility and change, Administrative Science Quarterly, 48(1), 94-118.

[16] Fornell, C. and Larcker, D. F. (1981). Evaluating structural equation models with unobservable variables and measurement error, Journal of Marketing Research, 18(1), 39-50.

[17] Frese, M. and Fay, D. (2001). Personal initiative: An active performance concept for work in the 21st century, Research in Organizational Behavior, 23, 133-187.

[18] Good, D. and Michel, E. J. (2013). Individual ambidexterity: Exploring and exploiting in dynamic contexts", The Journal of Psychology, 147(5), 435-453.

[19] Gosselin, E., Lemyre, L., and Corneil, W. (2013). Presenteeism and absenteeism: Differentiated understanding of related phenomena, Journal of Occupational Health Psychology, 18(1), 7586.

[20] Griffin, M. A., Neal, A., and Parker, S. K. (2007). A new model of work role performance: Positive behavior in uncertain and interdependent contexts, Academy of Management Journal, 50(2), 327-347.

[21] Hair, J. F., Anderson, R. E. and Talham, R. L. (1987). Multivariate data analysis with readings, MacMillan, New York, NY.

[22] Hair, J. F., Anderson, R. E., Tatham, R. L., and Black, W. C. (2010). Multivariate data analysis. Pearson, Upper Saddle, NJ.

[23] Harrison, D. and Price, K. H. (2003). Context and consistency in absenteeism: Studying social and dispositional influences across multiple settings, Human Resource Management Review, 13(2), 203-225.

[24] Huff, C. and Tingley, D. (2014). Evaluating the demographic characteristics and political preferences of MTurk survey respondents, working paper, Harvard University.

[25] Jasmand, C., Blazevic, V., and de Ruyter, K. (2012). Generating sales while providing service: A study of customer service representatives' ambidextrous behavior, Journal of Marketing, 76(1), 20-37.

[26] Junni, P., Sarala, R. M., Taras, V., and Tarba, S. Y. (2013). Organizational ambidexterity and performance: A meta-analysis, The Academy of Management Perspectives, 27(4), 299-312.

[27] Kauppila, O. P. (2010). Creating ambidexterity by integrating and balancing structurally separate interorganizational partnerships, Strategic Organization, 8(4), 283-312.

[28] Kauppila, O. P. and Tempelaar, M. P. (2016). The social-cognitive underpinnings of employees' ambidextrous behaviour and the supportive role of group managers' leadership, Journal of Management Studies, 53(6), 1019-1044.

[29] Keller, T. and Weibler, J. (2015), What it takes and costs to be an ambidextrous manager: Linking leadership and cognitive strain to balancing exploration and exploitation, Journal of Leadership and Organizational Studies, 22(1), 54-71.

[30] Kline, R. B. (2005), Principles and practice of structural equation modeling, Guilford Press, New York, NY.

[31] Kock, N. (2013), Using WarpPLS in e-collaboration studies: What if I have only one group and one condition? International Journal of E-Collaboration (IJeC), 9(3), 1-12.

[32] Kock, N. (2017), WarpPLS user manual: Version 6.0, Script Warp Systems, Laredo, TX.

[33] Kock, N., Jung, Y., and Syn, T. (2016). Wikipedia and e-collaboration research: Opportunities and challenges, International Journal of E-Collaboration (IJeC), 12(2), 1-8.

[34] Kock, N. and Lynn, G. (2012). Lateral collinearity and misleading results in variance-based SEM: An illustration and recommendations, Journal of the Association for Information Systems, 13(7), 546-580. 
[35] Li, C. R., Lin, C. J., and Tien, Y. H. (2015). CEO transformational leadership and top manager ambidexterity. Leadership \& Organization Development Journal, 36(2), 927-954.

[36] March, J. G. (1991). Exploration and exploitation in organizational learning, Organization Science, 2(1), 71-88.

[37] Martocchio, J. J. and Jimeno, D. I. (2003). Employee absenteeism as an affective event, Human Resource Management Review, 13(2), 227-241.

[38] Mayfield, J. and Mayfield, M. (2002). Leader communication strategies critical paths to improving employee commitment, American Business Review, 20(2), 89-94.

[39] Mayfield, J. and Mayfield, M. (2009). The role of leader motivating language in employee absenteeism, Journal of Business Communication, 46(4), 455-479.

[40] Mayfield, J. and Mayfield, M. (2018). Motivating language theory: Effective leader talk in the workplace. Palgrave Macmillan.

[41] Mayfield, J., Mayfield, M., and Kopf, J. (1995). Motivating language: Exploring theory with scale development, The Journal of Business Communication, 32(4), 329-344.

[42] Mayfield, M. and Mayfield, J. (2004). The effects of leader communication on worker innovation, American Business Review, 22(2), 46-51.

[43] Mayfield, M. and Mayfield, J. (2017). Leader talk and the creative spark: A research note on how motivating language use influences follower creative environment perceptions, International Journal of Business Communication, 54(2), 210-225.

[44] Miron-Spektor, E., Gino, F., and Argote, L. (2011). Paradoxical frames and creative sparks: Enhancing individual creativity through conflict and integration, Organizational Behavior and Human Decision Processes, 116(2), 229-260.

[45] Mom, T. J. M., Fourné, S. P. L., and Jansen, J. J. P. (2015). Managers' work experience, ambidexterity, and performance: The contingency role of the work context, Human Resource Management, 54(1), 133-153.

[46] Mom, T. J. M., Van Den Bosch, F. A. J., and Volberda, H. W. (2007),. Investigating managers' exploration and exploitation activities: The influence of top-down, bottom-up, and horizontal knowledge inflows, Journal of Management Studies, 44(6), 910-931.

[47] Mom, T. J. M., Van Den Bosch, F. A. J., and Volberda, H. W. (2009). Understanding variation in managers' ambidexterity: Investigating direct and interaction effects of formal structural and personal coordination mechanisms, Organization Science, 20(4), 812-828.

[48] Neves, P. and Eisenberger, R. (2014). Perceived organizational support and risk taking, Journal of Managerial Psychology, 29(2), 187-205.

[49] Nguyen, C. N., Mayfield, J., \& Mayfield, J. (2015). The rapport between perceived organizational support for development and worker outcomes, in M. Warkentin (Ed.), Models and Applications in the Decision Sciences: Best Papers from the 2015 Annual Conference. FT Press.

[50] Nunnally, J. C. and Berstein, I. H. (1994). Psychometric Theory, McGraw Hill, New York, NY.

[51] O'Reilly III, C. A. and Tushman, M. L. (2013). Organizational ambidexterity: Past, present, and future, The Academy of Management Perspectives, 27(4), 324-338.

[52] Parker, S. (2014). Beyond motivation: Job and work design for development, health, ambidexterity, and more, Annual Review of Psychology, 65, 661-691.

[53] Parker, S. K. (1998). Enhancing role breadth self-efficacy: the roles of job enrichment and other organizational interventions, Journal of Applied Psychology, 83(6), 835-852.

[54] Prieto, I. M. and Pilar Pérez Santana, M. (2012). Building ambidexterity: The role of human resource practices in the performance of firms from Spain, Human Resource Management, 51(2), 189-211.

[55] Raisch, S. and Birkinshaw, J. (2008). Organizational ambidexterity: Antecedents, outcomes, and moderators, Journal of Management, 34(3), 375-409. 
[56] Raisch, S., Birkinshaw, J., Probst, G., and Tushman, M. L. (2009). Organizational ambidexterity: Balancing exploitation and exploration for sustained performance, Organization Science, 20(4), 685-695.

[57] Rogan, M. and Mors, M. L. (2014). A network perspective on individual-level ambidexterity in organizations, Organization Science, 25(6), 1860-1877.

[58] Rogers, R. E. and Herting, S. R. (1993). Patterns of absenteeism among government employees, Public Personnel Management, 22(2), 215-235.

[59] Ryan, R. M. and Deci, E. L. (2000). Self-determination theory and the facilitation of intrinsic motivation, social development, and well-being, American Psychologist, 55(1), 68-78.

[60] Shook, C. L., Ketchen, D. J., and Hult, G. T. M. (2004). An assessment of the use of structural equation modeling in strategic management research, Strategic Management Journal, 25(4), 397-404.

[61] Simsek, Z. (2009). Organizational ambidexterity: Towards a multilevel understanding, Journal of Management Studies, 46(4), 597-624.

[62] Sok, P. and O'Cass, A. (2015). Examining the new product innovation - performance relationship: Optimizing the role of individual-level creativity and attention-to-detail, Industrial Marketing Management, 47, 156-165.

[63] Sullivan, J. J. (1988). Three roles of language in motivation theory, Academy of Management Review, 13(1), 104-115.

[64] Torres, J. P., Drago, C., and Aqueveque, C. (2015). Knowledge inflows effects on middle managers' ambidexterity and performance, Management Decision, 53(10), 2303-2320.

[65] Tremblay, M. A., Blanchard, C. M., Taylor, S., Pelletier, L. G., and Villeneuve, M. (2009). Work extrinsic and intrinsic motivation scale: Its value for organizational psychology research, Canadian Journal of Behavioural Science, 41(4), 213-226.

[66] Tushman, M. L. and O'Reilly III, C. A. (1996). Ambidextrous organizations: Managing evolutionary and revolutionary change, California Management Review, 38(4), 8-30.

[67] Wang, C. W., Fan, K. T., Hsieh, C. T., and Menefee, M. L. (2009). Impact of motivating language on team creative performance, The Journal of Computer Information Systems, 50(1), $133-140$. 